\title{
Efecto de tres ambientes de transporte sobre el tiempo de aparición de la autólisis en muestras de alevines de trucha arcoíris (Oncorhynchus mykiss)
}

\author{
Effect of three transport conditions on the appearance time of autolysis in samples \\ of rainbow trout fry (Oncorhynchus mykiss) \\ AR Ortloff ${ }^{a^{*}}$, PA Peña ${ }^{a}$, R Ildefonso \\ ${ }^{a}$ Escuela de Medicina Veterinaria, Universidad Católica de Temuco, Temuco, Chile.
}

\begin{abstract}
SUMMARY
The aim of this work was to compare three types of transport conditions on the appearance and progress of autolytic changes in samples of dead fry sent to be processed for histopathological analysis. 300 whole fry corpses were subjected to three transport conditions: submerged in water at $4{ }^{\circ} \mathrm{C}$, submerged in water at $15{ }^{\circ} \mathrm{C}$ and dry atmosphere at $4{ }^{\circ} \mathrm{C}$. Every hour from 0 to 24 hours, groups of 4 fry per condition were fixed in $10 \%$ formalin and processed using the conventional hematoxylin and eosin stain technique (H\&E). The appearance time of the autolytic changes in the different segments of the kidney and liver were determined in each group, classifying the changes as early autolytic, advanced autolytic and complete autolysis. It was observed that the autolytic changes appeared first in the livers of the corpses at $4{ }^{\circ} \mathrm{C}$ under dry condition while last ones to be affected were the corpses submerged in water at $4{ }^{\circ} \mathrm{C}\left(1\right.$ and 6 hours, respectively). The first autolytic changes appeared in the kidneys of the corpses at $4{ }^{\circ} \mathrm{C}$ in the dry atmosphere and the last in the corpses submerged in water at $4{ }^{\circ} \mathrm{C}$ ( 3 and 9 hours, respectively). It was concluded that out of the three transport conditions studied, the one preserving for longer the histological and cytological structure of the fish tissue for histological analysis was water preservation at $4{ }^{\circ} \mathrm{C}$, demonstrating the key role of the temperature and atmospheric humidity in the progress of fish autolysis.
\end{abstract}

Palabras clave: trucha arcoíris, autólisis, histología.

Key words: rainbow trout, autolysis, histology.

\section{INTRODUCCIÓN}

En acuicultura se realizan muestreos de tipo sanitario, epidemiológico y productivo. Los muestreos sanitarios consisten en la extracción y envío de muestras de peces enfermos (moribundos) o sanos a los laboratorios para el diagnóstico de enfermedades. Debido a las grandes distancias entre los laboratorios y los centros de cultivo es frecuente que en el traslado de las muestras muchos peces mueran, comenzando inmediatamente con el proceso de autólisis de los tejidos. Una de las técnicas diagnósticas usadas en la acuicultura es el análisis histopatológico de peces enfermos, siendo fundamental conocer si las alteraciones tisulares observadas corresponden a lesiones propias de una enfermedad o corresponden a cambios autolíticos producidos en los peces que han muerto en el trayecto (Tomita y col 2004).

La investigación histológica juega un rol importante en el examen post mórtem para dilucidar la causa y mecanismo de muerte y/o lesiones. En este contexto, al momento de evaluar deben tenerse en consideración los cambios autolíticos dependientes de condiciones ambientales como temperatura y humedad (Janssen 1984, Tomita y col 2004). Los cambios post mórtem en los peces habitualmente

Aceptado: 07.04.2011.

* Casilla 15 D, Temuco, Chile; aortloff@uct.cl siguen cuatro etapas: el rigor mortis, la resolución del mismo, autólisis y la descomposición bacteriana. Estas etapas se producen con mayor o menor rapidez, dependiendo de la especie, el estado fisiológico de los peces, la contaminación microbiana y la temperatura (Ayala y col 2010, Ocaño-Higuera y col 2009).

La autólisis celular es el proceso de desintegración que comienza luego de producida la muerte y en el cual no existe participación de bacterias, dependiendo sólo de la acción de las enzimas celulares (Trezza 2006). La autólisis de tejido normal producida en un individuo muerto se diferencia de la necrosis producida en individuos vivos, debido a que la primera es difusa y no involucra a células inflamatorias (Tomita y col 1999, 2004). En la autólisis, la secuencia de eventos que se generan comienza con el déficit celular de oxígeno, produciendo daños irreversibles en la estabilidad de la membrana celular, en la síntesis de proteínas, la cadena respiratoria celular y en el material nuclear. La desestabilización estructural de las membranas celulares y de sus organelos genera profundos cambios en el intercambio iónico y de fluidos, los que adicionados a los cambios hidroelectrolíticos y del $\mathrm{pH}$ celular alteran progresivamente las estructuras de los organelos citoplasmáticos, generando la liberación de enzimas hidrolíticas al citoplasma conllevando la digestión de los distintos constituyentes celulares. Este proceso depende de diversos factores como el tipo de tejido y la condición nutricional previa del sujeto, entre otros (Trezza 2006). 
En mamíferos se han descrito la morfología y la ultraestructura de los cambios post mórtem producidos bajo distintas condiciones de temperatura para diversos órganos (Ilse y col 1979, Andersson y Collins 1983, El-Shennawy y col 1985, Cingolani y col 1994, Tomita y col 1999). En el caso de los peces se han realizado varios estudios que evalúan los cambios post mórtem, específicamente en el músculo esquelético, por ser este órgano de interés comercial (Caballero y col 2009, Ocaño-Higuera y col 2009, Ayala y col 2010). Sin embargo, no existen estudios que determinen y caractericen en el tiempo, bajo condiciones controladas, la aparición del proceso de autólisis en órganos de interés sanitario.

Este estudio comparó tres condiciones ambientales de transporte de alevines, analizando histológicamente el tiempo de aparición de los procesos autolíticos en tejido renal y hepático.

\section{MATERIAL Y MÉTODOS}

\section{MATERIAL BIOLÓGICO}

Se utilizaron 300 alevines de trucha arcoíris (Oncorhynchus mykiss) con un peso promedio de $1 \mathrm{gr}$ adquiridos de una piscicultura ubicada en Región de La Araucanía (Chile), la cual presentaba mortalidades promedio de $0,01 \% /$ día. Los ejemplares fueron mantenidos en el laboratorio de Ictiopatología de la Universidad Católica de Temuco en estanques de fibra de vidrio, bajo las mismas condiciones de cultivo relacionados con la densidad $\left(20 \mathrm{~kg} / \mathrm{m}^{3}\right)$, temperatura del agua $\left(10^{\circ} \mathrm{C}\right)$ y horas/luz (24 horas). Los peces fueron mantenidos en aclimatación durante $24 \mathrm{~h}$, tiempo en el cual se mantuvieron en ayuno. Posterior a la aclimatación, se procedió a extraer los peces de forma individual, realizando la eutanasia mediante contusión cerebral aguda. Las muestras se distribuyeron en tres grupos según las distintas condiciones ambientales de transporte estudiadas.

\section{CONDICIONES AMBIENTALES DE TRANSPORTE Y CONSERVACIÓN}

Se compararon tres condiciones ambientales de transporte de muestras de alevines sin fijar: (i) Alevines muertos sumergidos en agua de la piscicultura mantenidos a $4{ }^{\circ} \mathrm{C}$, (ii) alevines muertos sumergidos en agua de la piscicultura a temperatura ambiente constante de $15^{\circ} \mathrm{C}$ y (iii) alevines muertos almacenados sin agua (seco) en ambiente refrigerado a $4{ }^{\circ} \mathrm{C}$. Las condiciones ambientales (i) y (iii) fueron conservadas a $4{ }^{\circ} \mathrm{C}$ en un refrigerador, con monitoreo de la temperatura por medio de un termómetro de máxima y mínima, asegurándose que la temperatura se mantuviera constante y con una fluctuación de $\pm 1{ }^{\circ} \mathrm{C}$ durante todo el experimento. Las tres condiciones intentan recrear situaciones de transporte de muestras en terreno, y se basaron en los siguientes criterios: i) $4{ }^{\circ} \mathrm{C}$ es la temperatura en la que frecuentemente están los equipos de refrigeración, por lo que es probable que al momento de enviar muestras desde el centro de cultivo hasta el laboratorio se procure mantener esta temperatura mediante el uso de hielo y otro elemento que mantenga el frío en el transporte. ii) $15^{\circ} \mathrm{C}$ es la temperatura ambiental promedio a la que se mantiene el agua cuando es transportada sin un medio refrigerante (esto fue registrado empíricamente transportando agua de una piscicultura en buses de servicio regular de encomienda), por lo que representa otra condición probable de transporte en la práctica cuando no se cuenta con hielo $\mathrm{u}$ otro elemento que mantenga el frío. iii) $4{ }^{\circ} \mathrm{C}$ sin agua (en seco) es una condición de transporte utilizada para enviar muestras cuando las empresas de encomienda no aceptan transportar medios líquidos, por lo que las muestras son transportadas en seco y con elementos de enfriamiento.

OBTENCIÓN DE MUESTRAS, PROCESAMIENTO Y CRITERIOS DE ANÁLISIS

Para cada condición descrita anteriormente se extrajeron cuatro alevines (cuadruplicado) al tiempo cero (controles) y cada hora hasta la hora 24. A los cuatro cadáveres de alevines de cada muestreo se les realizó una incisión en la región ventral para favorecer la penetración de la solución fijadora (formalina tamponada al 10\%), siendo mantenidos en contenedores rotulados durante $48 \mathrm{~h}$. Una vez fijados todos los cadáveres, fueron procesados simultáneamente mediante técnica histológica convencional (Kiernan 2008). Durante el proceso de inclusión, los cadáveres de alevines fueron orientados longitudinalmente, a fin de obtener secciones histológicas que permitan la observación de todos los órganos ubicados medial y paramedialmente. Para esto se seleccionaron tres cortes de $5 \mu \mathrm{m}$ de grosor (uno medial y dos paramediales) que en conjunto tenían secciones de hígado, riñón, estómago, intestinos y ciegos pilóricos. Los cortes fueron montados en portaobjetos y teñidos con tinción convencional de hematoxilina y eosina. De cada corte histológico se analizó hígado completo (superficie en contacto con pared abdominal y cara medial en contacto con estómago) y riñón (región anterior, media y posterior). Se analizaron la preservación de la arquitectura histológica del órgano, las características citoplasmáticas y nucleares de los hepatocitos, de las células epiteliales de los túbulos contorneados, tejido hematopoyético y eritrocitos. Como signo de autólisis se consideró: (i) el incremento de la eosinofilia citoplasmática, (ii) presencia de núcleos con cromatina condensada, o con cariólisis, (iii) tumefacción del citoplasma y (iv) pérdida del detalle estructural de las células, así como de sus límites nuclear y citoplasmático.

Se definieron arbitrariamente tres estados de autólisis: i) Autólisis temprana: en riñón, se caracterizó porque la mayoría de los túbulos contorneados distales y proximales cortados transversalmente presentaban hasta cuatro células con núcleo con cromatina condensada y/o cariorrexis, aumento de la eosinofilia citoplasmática si se 
comparaba con las vecinas, se mantenía la unión entre las células epiteliales tubulares y la arquitectura del órgano se conservaba, reconociéndose las unidades estructurales y funcionales. En el hígado se analizó en aumento 100X y este estado se caracterizó por la presencia de eritrocitos con núcleo con cromatina condensada y hemólisis, y menos del $15 \%$ de los hepatocitos por campo con núcleo con cromatina condensada, cariorrexis y/o cariólisis y eosinofilia citoplasmática. Los límites citoplasmáticos de los hepatocitos se mantenían definidos. ii) Autólisis avanzada: en riñón se caracterizó porque la mayoría de los túbulos contorneados distales y proximales cortados transversalmente presentaban más de cuatro núcleos con cromatina condensada y/o con cariorrexis, aumento de la eosinofilia citoplasmática y pérdida de la unión entre células epiteliales. Los límites citoplasmáticos se mantenían definidos. En hígado se caracterizó porque más del 15\% de los hepatocitos tenían cambios nucleares y citoplasmáticos autolíticos, sin embargo fue posible reconocer los límites citoplasmáticos que definían un hepatocito. iii) Autólisis completa: en el riñón se caracterizó por la severa distorsión de la arquitectura histológica, reconociéndose sólo vestigios de las principales estructuras renales. No fue posible reconocer células individualmente, las cuales aparecieron como estructuras eosinófilas amorfas. Las células del tejido hematopoyético se reconocieron, pero no fue posible su caracterización e identificación. El hígado se caracterizó por la severa distorsión de la arquitectura histológica, reconociéndose sólo vestigios de las principales estructuras hepáticas. En la mayoría de los cortes no fue posible reconocer en detalle hepatocitos individualmente, los cuales aparecieron como estructuras eosinófilas amorfas, con restos basófilos que correspondían al núcleo.

\section{ANÁLISIS DE LAS MUESTRAS HISTOLÓGICAS}

El análisis de las muestras histológicas fue realizado con un microscopio marca Olympus modelo BX-41, las imágenes fueron capturadas con una cámara marca Jenoptik modelo ProgRes C3, y el análisis de imágenes se realizó con el software ProgRes® Mac CapturePro 2.7.6. El análisis de las imágenes consistió en la identificación y el conteo de núcleos con cambios autolíticos para clasificar a la muestra dentro de los tres estados de autólisis.

\section{RESULTADOS Y DISCUSIÓN}

En el cuadro 1 se presentan los distintos tiempos de aparición de los cambios autolíticos en riñón e hígado en los tres tratamientos.

RIÑÓN

Se observaron diferencias en cuanto a los tiempos de aparición de los cambios autolíticos entre las tres regiones del riñón. Independiente de la condición ambiental evaluada, en las regiones media y posterior del riñón los cambios autolíticos se presentaron en el mismo período de tiempo, a diferencia del riñón anterior, cuyos cambios autolíticos aparecieron una hora antes, patrón que se repitió en las tres condiciones ambientales (cuadro 1). Las características morfológicas de los tres períodos de autólisis que se

Cuadro 1. Tiempo de aparición de los cambios autolíticos tempranos, avanzados y autólisis completa entre los tres ambientes de transporte: sumergidos agua a $4{ }^{\circ} \mathrm{C}(\mathrm{A})$; sumergidos agua a $15^{\circ} \mathrm{C}(\mathrm{B})$; ambiente seco a $4{ }^{\circ} \mathrm{C}(\mathrm{C})$.

Appearance time of the early and advanced autolytic changes and complete autolysis in the three transport atmospheres: submerged water at $4{ }^{\circ} \mathrm{C}(\mathrm{A})$; submerged water at $15{ }^{\circ} \mathrm{C}(\mathrm{B})$; dry atmosphere at $4{ }^{\circ} \mathrm{C}(\mathrm{C})$.

\begin{tabular}{|c|c|c|c|c|c|}
\hline & & \multicolumn{4}{|c|}{ PROCESO DE AUTÓLISIS } \\
\hline & & Órgano & Temprana & Avanzada & Completa \\
\hline \multirow{15}{*}{ 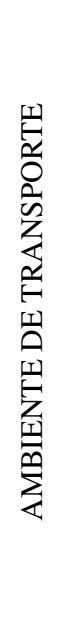 } & \multirow{5}{*}{ A } & Hígado cara medial & $5 \mathrm{~h}$ & $20 \mathrm{~h}$ & $23 \mathrm{~h}$ \\
\hline & & Hígado cara lateral & $6 \mathrm{~h}$ & $21 \mathrm{~h}$ & $24 \mathrm{~h}$ \\
\hline & & Riñón anterior & $8 \mathrm{~h}$ & $14 \mathrm{~h}$ & $17 \mathrm{~h}$ \\
\hline & & Riñón medio & $9 \mathrm{~h}$ & $15 \mathrm{~h}$ & $18 \mathrm{~h}$ \\
\hline & & Riñón posterior & $9 \mathrm{~h}$ & $15 \mathrm{~h}$ & $18 \mathrm{~h}$ \\
\hline & \multirow{5}{*}{ B } & Hígado cara medial & $2 \mathrm{~h}$ & $14 \mathrm{~h}$ & $17 \mathrm{~h}$ \\
\hline & & Hígado cara lateral & $3 \mathrm{~h}$ & $15 \mathrm{~h}$ & $18 \mathrm{~h}$ \\
\hline & & Riñón anterior & $5 \mathrm{~h}$ & $11 \mathrm{~h}$ & $14 \mathrm{~h}$ \\
\hline & & Riñón medio & $6 \mathrm{~h}$ & $12 \mathrm{~h}$ & $15 \mathrm{~h}$ \\
\hline & & Riñón posterior & $6 \mathrm{~h}$ & $12 \mathrm{~h}$ & $15 \mathrm{~h}$ \\
\hline & \multirow{5}{*}{$\mathrm{C}$} & Hígado cara medial & $1 \mathrm{~h}$ & $5 \mathrm{~h}$ & $8 \mathrm{~h}$ \\
\hline & & Hígado cara lateral & $1 \mathrm{~h}$ & $6 \mathrm{~h}$ & $9 \mathrm{~h}$ \\
\hline & & Riñón anterior & $2 \mathrm{~h}$ & $8 \mathrm{~h}$ & $11 \mathrm{~h}$ \\
\hline & & Riñón medio & $3 \mathrm{~h}$ & $9 \mathrm{~h}$ & $12 \mathrm{~h}$ \\
\hline & & Riñón posterior & $3 \mathrm{~h}$ & $9 \mathrm{~h}$ & $12 \mathrm{~h}$ \\
\hline
\end{tabular}


definieron para el riñon pueden observarse en la figura 1: autólisis temprana (figura 1a, d, g), autólisis avanzada (figura $1 \mathrm{~b}, \mathrm{e}, \mathrm{h}$ ) y autólisis completa (figura 1c, f, i).

HÍGADO

En la región medial del hígado, que está en estrecho contacto con el estómago, los cambios autolíticos aparecen aproximadamente una hora antes si se compara con otras regiones del mismo órgano (para comparar los tiempos, ver cuadro 1). Este patrón se repitió en las tres condiciones ambientales. Las características morfológicas de los tres períodos de autólisis que se definieron para el hígado pueden observarse en la figura 1: autólisis temprana (figura 2a, d, g), autólisis avanzada (figura $2 \mathrm{~b}, \mathrm{e}, \mathrm{h}$ ) y autólisis completa (figura 2c, f, i).

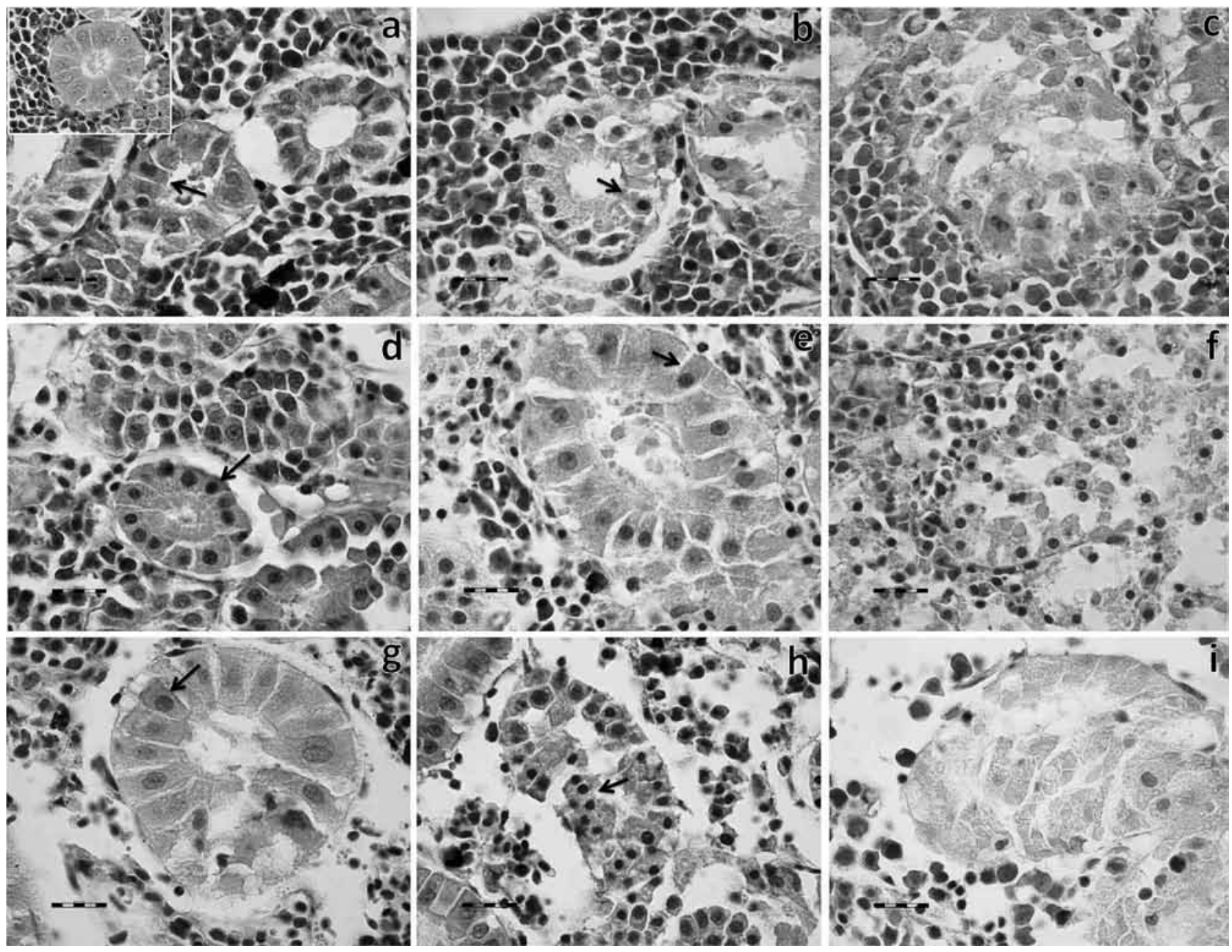

Figura 1. Cortes histológicos de la región anterior de riñones de alevines de trucha arcoíris. a, d, g: Cambios autolíticos tempranos de alevines mantenidos sumergidos en agua a $4{ }^{\circ} \mathrm{C}(8 \mathrm{~h})$, sumergidos en agua a $15^{\circ} \mathrm{C}(5 \mathrm{~h})$ y en ambiente seco a $4{ }^{\circ} \mathrm{C}(2 \mathrm{~h})$, respectivamente. Túbulo contorneado con estructura histológica conservada, célula epitelial con eosinofilia citoplasmática y núcleo con concentración de la cromatina (flecha). Inserto: riñón fijado inmediatamente después de la muerte (control). b, e, h: Cambios autolíticos avanzados de cadáveres de alevines mantenidos sumergidos en agua a $4{ }^{\circ} \mathrm{C}(14 \mathrm{~h})$, sumergidos en agua a $15^{\circ} \mathrm{C}(11 \mathrm{~h})$ y en ambiente seco a $4{ }^{\circ} \mathrm{C}(8$ h), respectivamente. Aumento en el número de células con núcleo con su cromatina concentrada (flecha) y desprendimiento de células epiteliales tubulares, desorganizando parcialmente la estructura histológica renal. c, f, i: Autólisis completa de cadáveres de alevines mantenidos sumergidos en agua a $4{ }^{\circ} \mathrm{C}(17 \mathrm{~h})$, sumergidos en agua a $15^{\circ} \mathrm{C}(14 \mathrm{~h})$ y en ambiente seco a $4{ }^{\circ} \mathrm{C}(11 \mathrm{~h})$, respectivamente. Estructura histológica está completamente alterada, las células aparecen como estructuras eosinófilas amorfas sin detalle ni límite citoplasmático definido. (H\&E); Escala: $20 \mu \mathrm{m}$.

Histological cuts of rainbow trout fry kidneys. a, d, g: Early autolytic changes in fry corpses maintained submerged in water at $4{ }^{\circ} \mathrm{C}(8 \mathrm{~h})$, submerged in water at $15{ }^{\circ} \mathrm{C}(5 \mathrm{~h})$ and in a dry atmosphere at $4{ }^{\circ} \mathrm{C}(2 \mathrm{~h})$, respectively. Convoluted tubuli with histological structure preserved, epithelial cell with cytoplasmic eosinophilia and nucleus with concentration of chromatin (arrow). Insert: Kidney fixed immediately after death (control). b, e, h: Advanced autolytic changes in fry corpses maintained submerged in water at $4{ }^{\circ} \mathrm{C}(14 \mathrm{~h})$, submerged in water at $15^{\circ} \mathrm{C}(11 \mathrm{~h})$ and in a dry atmosphere at $4{ }^{\circ} \mathrm{C}(8 \mathrm{~h})$, respectively. Increase in the number of cells with nucleus with its chromatin concentrated (arrow) and detachment of tubular epithelial cells, partially disrupting the histological structure of the kidney. c, f, i: Complete autolysis in fry corpses maintained submerged in water at $4{ }^{\circ} \mathrm{C}(17 \mathrm{~h})$, submerged in water at $15{ }^{\circ} \mathrm{C}(14 \mathrm{~h})$ and in a dry atmosphere at $4{ }^{\circ} \mathrm{C}(11 \mathrm{~h})$, respectively. Histological structure is completely altered, the cells appear as amorphous eosinophilic structures with no detail or defined cytoplasmic limit. (H\&E); Scale: $20 \mu \mathrm{m}$. 

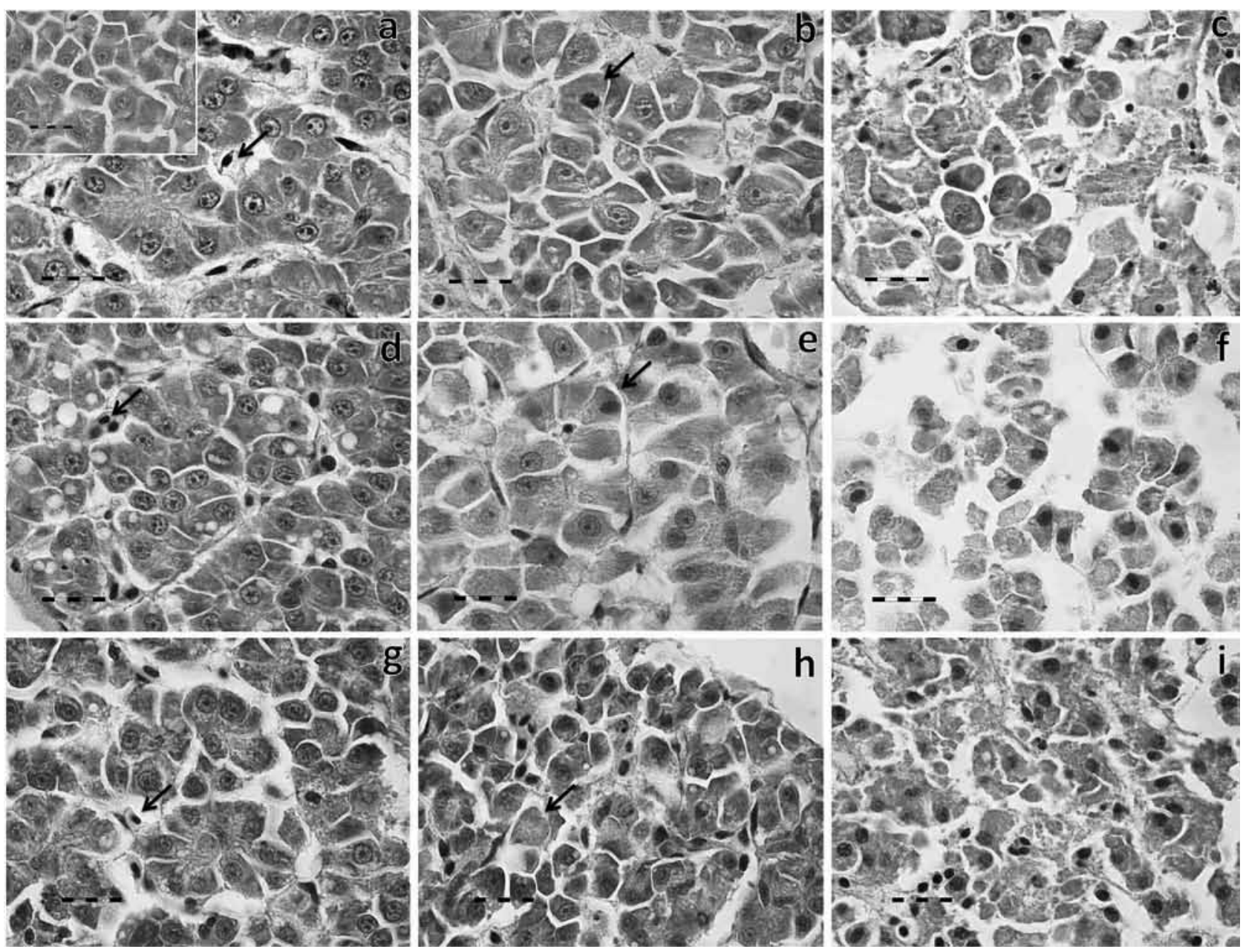

h

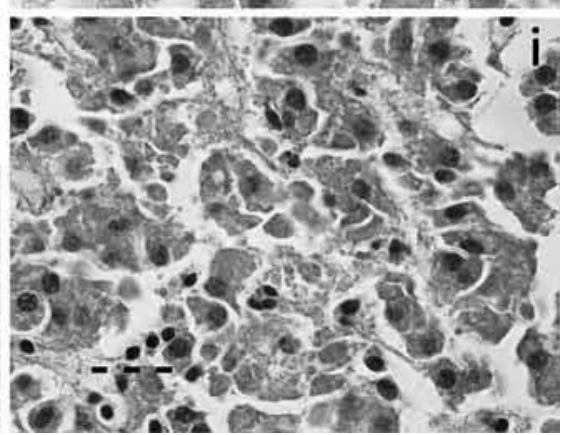

Figura 2. Cortes histológicos de región lateral de hígados de alevines de trucha arcoíris. a, d, g: Cambios autolíticos tempranos de cadáveres de alevines mantenidos sumergidos en agua a $4{ }^{\circ} \mathrm{C}(6 \mathrm{~h})$, sumergidos en agua a $15{ }^{\circ} \mathrm{C}(3 \mathrm{~h})$ y en ambiente seco a $4{ }^{\circ} \mathrm{C}(1 \mathrm{~h})$, respectivamente. Cromatina concentrada en núcleo de eritrocitos (flecha) y leve tumefacción de los hepatocitos. La estructura histológica está conservada. Inserto: hígado fijado inmediatamente después de la muerte (control). b, e, h: Cambios autolíticos avanzados de cadáveres de alevines mantenidos sumergidos en agua a $4{ }^{\circ} \mathrm{C}(21 \mathrm{~h})$, sumergidos en agua a $15{ }^{\circ} \mathrm{C}(15 \mathrm{~h})$ y en ambiente seco a $4{ }^{\circ} \mathrm{C}$ $(6 \mathrm{~h})$, respectivamente. Aumento en el número de células con eosinofilia citoplasmática, núcleo con cromatina concentrada (flecha) y/o agregación de la cromatina en el borde del núcleo. Pérdida parcial de la estructura histológica hepática. c, f, i: Autólisis completa de cadáveres de alevines mantenidos sumergidos en agua a $4{ }^{\circ} \mathrm{C}(24 \mathrm{~h})$, sumergidos en agua a $15{ }^{\circ} \mathrm{C}(18 \mathrm{~h})$ y en ambiente seco a $4{ }^{\circ} \mathrm{C}$ $(9 \mathrm{~h})$, respectivamente. Estructura histológica completamente alterada, la mayoría de las células aparecen como estructuras eosinófilas amorfas sin detalle ni límite citoplasmático definido. (H\&E); Escala: $20 \mu \mathrm{m}$.

Histological cuts of rainbow trout fry livers. a, d, g: Early autolytic changes in fry corpses maintained submerged in water at $4{ }^{\circ} \mathrm{C}(6 \mathrm{~h})$, submerged in water at $15{ }^{\circ} \mathrm{C}(3 \mathrm{~h})$ and in a dry atmosphere at $4{ }^{\circ} \mathrm{C}(1 \mathrm{~h})$, respectively. Erythrocytes with nuclear concentration of chromatin (arrow), slight swelling of hepatocytes with histological structure preserved. Insert: Liver fixed immediately after death (control). b, e, h: Advanced autolytic changes in fry corpses maintained submerged in water at $4{ }^{\circ} \mathrm{C}(21 \mathrm{~h})$, submerged in water at $15^{\circ} \mathrm{C}(15 \mathrm{~h})$ and in a dry atmosphere at $4{ }^{\circ} \mathrm{C}(6 \mathrm{~h})$, respectively. Increase in the number of cells with citoplasmic eosinopfilia with its nuclear chromatin concentrated (arrow) and/or aggregation of chromatin in the nuclear border, partially disrupting the histological structure of the liver. $\mathbf{c}, \mathbf{f}, \mathbf{i}$ : Complete autolysis in fry corpses maintained submerged in water at $4{ }^{\circ} \mathrm{C}(24 \mathrm{~h})$, submerged in water at $15{ }^{\circ} \mathrm{C}(18 \mathrm{~h})$ and in a dry atmosphere at $4{ }^{\circ} \mathrm{C}(9 \mathrm{~h})$, respectively. Histological structure is completely altered, the cells appear as amorphous eosinophilic structures with no detail or defined cytoplasmic limit. (H\&E); Scale: $20 \mu \mathrm{m}$.

Se observó que los cambios autolíticos, tanto en hígado como riñón, se presentaron primero en los cadáveres de alevines que fueron mantenidos a $4^{\circ} \mathrm{C}$ en ambiente seco, seguido por el grupo de alevines mantenidos sumergidos en agua a temperatura ambiente de $15^{\circ} \mathrm{C}$. El grupo que mantuvo por más tiempo la integridad histológica fue el de los cadáveres mantenidos sumergidos en agua a $4{ }^{\circ} \mathrm{C}$.
Estos resultados podrían explicarse en parte porque la temperatura ambiental influye directamente en la temperatura corporal de los peces. Cuando la temperatura es baja, el pH se mantiene elevado por más tiempo y el metabolismo celular disminuye, resultando en una autólisis más lenta (Berka 1986, Gunn 2009). Complementariamente a la temperatura se debe considerar el efecto que posee 
la sumersión en agua o humedad de las muestras. Para muestras sumergidas, la descomposición es dos veces más lenta que si estuvieran expuestas al aire, debido a que el oxígeno es necesario en los procesos oxidativos de la descomposición, siendo la concentración menor en el agua que en el aire (Dent y col 2004, Gunn 2009). Si bien el fenómeno de descomposición es diferente a la autólisis, ambos procesos ocurren casi en forma simultánea, especialmente en cuerpos de menor superficie en ambientes con abundante flora bacteriana saprófita, y los efectos de uno de estos fenómenos influyen sobre el desarrollo del otro. Posiblemente en las muestras del ambiente frío y seco el efecto del ambiente aerobio predominó sobre el efecto retardante de la temperatura baja, aumentando la velocidad de descomposición y autólisis de las muestras. Adicionalmente se observó que el proceso de autólisis comienza antes en el tejido hepático y riñón anterior que en el tejido renal medio y posterior. Esto podría explicarse por la estrecha relación anatómica topográfica entre el hígado (región medial) y riñón anterior con el estómago, el cual se observó desintegrado y con su contenido libre por lo menos una hora antes de que se observaran los primeros cambios tanto en hígado como en riñón. Esto facilitaría la autólisis y descomposición, especialmente en las regiones con mayor contacto debido a la actividad química y enzimática del contenido gástrico post mórtem (Trezza 2006). En este mismo contexto, el riñón se mantiene por más tiempo aislado anatómicamente del aparato digestivo por medio de la vejiga natatoria, impidiendo momentáneamente el contacto con las enzimas digestivas de los jugos gástricos en las primeras etapas post mórtem, las cuales aceleran los procesos de descomposición y autólisis.

De acuerdo con los resultados de este estudio se concluye que, para condiciones de terreno en las que no se disponga de métodos químicos de fijación de tejidos, las muestras de alevines vivos, agónicos o muertos destinadas a análisis histopatológico se transporten sumergidos en agua a $4{ }^{\circ} \mathrm{C}$, siendo fijados al llegar al laboratorio de análisis antes de los tiempos de autólisis descritos en el cuadro 1.

\section{RESUMEN}

El objetivo de este trabajo fue comparar el efecto de tres tipos de ambiente de transporte sobre el tiempo de aparición y progreso de los cambios autolíticos de muestras de alevines muertos, enviados para ser procesados para análisis histopatológico. Para ello se depositaron 300 cadáveres de alevines completos en tres ambientes de transporte: sumergidos agua a $4{ }^{\circ} \mathrm{C}$, sumergidos agua a $15^{\circ} \mathrm{C}$ y ambiente seco a $4{ }^{\circ} \mathrm{C}$. Cada una hora, desde el tiempo cero hasta las 24 horas, grupos de 4 alevines por ambiente fueron fijados en formalina al $10 \%$ y procesados con la técnica histológica convencional de hematoxilina\&eosina. En todos los grupos se determinó el tiempo de aparición de los cambios autolíticos en los distintos segmentos del riñón e hígado, clasificándose en cambios autolíticos tempranos, avanzados y autólisis completa. Se observó que los cambios autolíticos se evidencian primero en los hígados de los cadáveres a $4{ }^{\circ} \mathrm{C}$ en ambiente seco y al último en los cadáveres sumergidos en agua a $4{ }^{\circ} \mathrm{C}$ ( 1 y 6 horas, respectivamente). Respecto al riñón, los primeros cambios autolíticos se presentaron en cadáveres a $4{ }^{\circ} \mathrm{C}$ en ambiente seco y al último en los cadáveres sumergidos en agua a $4{ }^{\circ} \mathrm{C}$ ( 3 y 9 horas, respectivamente). De este estudio se concluye que de los tres ambientes de transporte comparados, el que conserva por más tiempo la estructura histológica y citológica de los tejidos de los peces para análisis histológico es la conservación sumergidos en agua a $4{ }^{\circ} \mathrm{C}$, evidenciando el rol clave de la temperatura y humedad ambiental en el progreso de la autólisis de peces.

\section{REFERENCIAS}

Andersson B, VP Collins. 1983. Post mortem, ultrastructural cardiac muscle changes and anthracycline toxicity. Biomed Pharmacother 37, 281-287.

Ayala MD, I Abdel, M Santaella, C Martínez, MJ Periago, F Gil, A Blanco, O Albors. 2010. Muscle tissue structural changes and texture development in sea bream, Sparus aurata L., during post-mortem storage. LWT-Food Science and Technology 43, 465-475.

Berka R. 1986. The transport of live fish. A review. EIFAC Tech Pap 48, 52.

Caballero M, M Betancor, J Escrig, D Montero, A Espinosa de los Monteros, P Castro, R Ginés, M Izquierdo. 2009. Post mortem changes produced in the muscle of sea bream (Sparus aurata) during ice storage. Aquaculture 291, 210-216.

Cingolani M, A Osculati, A Tombolini, A Tagliabracci, C Ghimenton, SD Ferrara. 1994. Morphology of sweat glands in determining time of death. Int J Legal Med 107, 132-140.

Dent BB, SL Forbes, BH Stuart. 2004. Review of human decomposition processes in soil. Environ Geol 45, 576-585.

El-Shennawy IE, DJ Gee, SR Aparicio. 1985. Renal tubular epithelia ultrastructure in autolysis. The J Pathol 147, 13-21.

Gunn A. 2009. Essential forensic biology. $2^{\text {nd }}$ ed. Wiley-Blackwell, Oxford, UK, Pp 424.

Ilse G, K Kovacs, N Ryan, E Horvath, D Ilse. 1979. Autolytic changes in the rat adenohypophysis. A histologic, immunocytologic and electron microscopic study. Exp Pathol (Jena) 17, 185-195.

Janssen W. 1984. Forensic histopathology. Springer-Verlag, Berlin, Alemania, Pp 402.

Kiernan JA. 2008. Histological and Histochemical Methods: Theory and Practice. $4^{\text {th }}$ ed. Scion Publishing Ltd., Oxfordshire, UK, Pp 576.

Ocaño-Higuera V, E Marquez-Ríos, M Canizales-Dávila, F CastilloYáñez, R Pacheco-Aguilar, M Lugo-Sánchez, K García-Orozco, AZ Graciano-Verdugo. 2009. Postmortem changes in cazon fish muscle stored on ice. Food Chemistry 116, 933-938.

Tomita Y, M Nihira, Y Ohno, S Sato. 1999. Histological study of early postmortem changes in various organs: comparison of the paraffin embedding method and the epoxy resin embedding method. Jpn J Legal Med 53, 207-217.

Tomita Y, M Nihira, Y Ohno, S Sato. 2004. Ultrastructural changes during in situ early postmortem autolysis in kidney, pancreas, liver, heart and skeletal muscle of rats. Legal Med 6, 25-31.

Trezza F. 2006. Data de la muerte: las transformaciones cadavéricas. Dosyuna Ediciones Argentinas, Buenos Aires, Argentina, Pp 256. 